\title{
The calorie burning calculation system in jogging using a thresholding-based accelerometer sensor
}

\author{
Finanta Okmayura*1, Adlian Jefiza ${ }^{2}$, Witri Ramadhani ${ }^{3}$ \\ Universitas Muhammadiyah Riau, Indonesia ${ }^{1,3}$ \\ Politeknik Negeri Batam, Indonesia ${ }^{2}$
}

\section{Article Info}

Keywords:

Accelerometer, Sensor, Thresholding, Calorie

Burning, Jogging

\section{Article history:}

Received 10 December 2019

Revised 14 April 2020

Accepted 30 April 2020

Available 06 May 2020

\section{Cite:}

Okmayura, F., Jefiza, A., \& Ramadhani, W. (2020). The calorie burning calculation system in jogging using a thresholding-based accelerometer sensor. Kinetik: Game

Technology, Information System, Computer Network, Computing, Electronics, and Control, 5(2).

doi:https://doi.org/10.22219/kinetik.v5i2.1005

${ }^{*}$ Corresponding author.

Finanta Okmayura

E-mail address:

finantaokmayura@umri.ac.id

\begin{abstract}
Jogging has benefits for burning calories as well as for losing the weight of the body. However, the reality that often happens is that sportsmen overwork their body in exercising so that it has passed its normal threshold. This causes over or lower calorie burning in these athletes. To overcome these problems, we need a device that can later monitor calorie burning. This device is created on an Android-based platform using an accelerometer sensor. Using this sensor, the system can count the number of a person's steps previously obtained through the threshold value as the threshold value to determine the steps. Calculation of calorie burning uses a formula that involves the number of footsteps, time, and weight of the user. This application testing involved 15 participants by comparing the calorie burning results through the application and manual calculation, so that the overall error percentage of $0.60 \%$ was obtained, so it can be concluded that $99.40 \%$ of the calorie burning calculation system in jogging using a thresholding-based accelerometer sensor is appropriate for athletes to provide information of their calories burning in jogging.
\end{abstract}

\section{Introduction}

Exercise requires energy which is known in kilos of calories. This energy source comes from fat or from glycogen [1]. It is really often found in public society that if someone does exercise continuously it will make them get the ideal body weight and body shape. This is to ensure a healthier lifestyle and to reduce health problems [2].This paradigm has been very united in people who are obese. The rise of obesity as a global epidemic makes it immensely important to monitor food habits of a modern day person [3]. Because obese people are very worried about losing weight, they regularly need to check the weight lost during exercise [4]. One of the easiest sport and easy to do to get the ideal weight is jogging. Jogging is a sport that is very effective in burning calories in the body. Jogging is a type of casual running that is meant to be less stressful than running. Usually this type of exercise is performed remotely and a period of time. Calories burned while running cause $90 \%$ more weight loss than just walking alone. Jogging is a very effective sport so that an athlete must monitor the calorie burning in his body.

However, it was often found that the athletes tend to do exercise without measuring the amount of calorie burning during exercise. Whereas, this is very important because an athlete must know how many calories there are in his body and what is the ideal number of calories for his body. But In fact that the athlete often pushes his body into exercise so that it has exceeded its normal limits, even though the calorie content in the body is also very necessary. of course this is very fatal for the athlete himself since this can cause over or lower combustion.

To overcome these problems, we need a device that can later monitor calorie burning. This device is built on an Android-based platform using an accelerometer sensor. Using this sensor, the system can count the number of a person'ssteps previously obtained through the threshold value as the threshold value to determine the step. Calculation of calorie burning uses a formula that involves the number of footsteps, time, and weight of the user [5].

In a previous study, most cellular-based solutions for dealing with management fall only with accelerometer data [6]. An accelerometer sensor is used by placing a sensor on one of the patient's legs to determine the number of calories that will burn for medical rehabilitation patients [7]. In addition, the detection of steps on android smartphones using the accelerometer sensor was still limited by the Dead Reckoning method and could not yet display the intake of lost calorie substitutes [8]. Therefore, researchers are interested in developing an Android-based device with a thresholding-based accelerometer sensor to monitor one's calorie burning.

Cite: Okmayura, F., Jefiza, A., \& Ramadhani, W. (2020). The calorie burning calculation system in jogging using a thresholding-based accelerometer sensor. Kinetik: Game Technology, Information System, Computer Network, Computing, Electronics, and Control, 5(2). doi:https://doi.org/10.22219/kinetik.v5i2.1005 
Based on the problems that have been described previously, the authors were interested in applying the use of thresholding-based accelerometer sensor to calculate the calorie burning in jogging on the Android platform. The results of this study were expected to help and facilitate athletes in controlling their calorie combustion.

\section{Literature Review}

\subsection{Calculation of Calorie Burning}

Basal Metabolic Rate (BMR) is the number of daily calories which the body needs to survive and perform physical activity. To carry out its functions, all internal organs of the human body burn calories. It is the average of 60$70 \%$ of the total calories which is spent in a day. To reduce $1 \mathrm{~kg}$ of body fat, it requires a calorie deficit of around 7200 kcals. After knowing the IMT who is obese, it can be seen how many $\mathrm{kg}$ of fat must be reduced, so it can also be known how many calories must be existed and must be burned in the body.

For every sport movement, the MET (metabolic equivalent of task) value is sough which is the estimated number of calories burned while doing sports activities within a certain time; then compared with the estimated body muscle mass volume. In addition to finding calories burned while exercising, the same calculation can also be used to calculate how many calories are burned for daily activities. The basic formula of MET can be seen on Equation 1 below.

$$
E C=\left\{\operatorname{MET} \times 7.7 \times \frac{(B B \times 2.2)}{200}\right\} \times \frac{\text { Duration }}{60}
$$

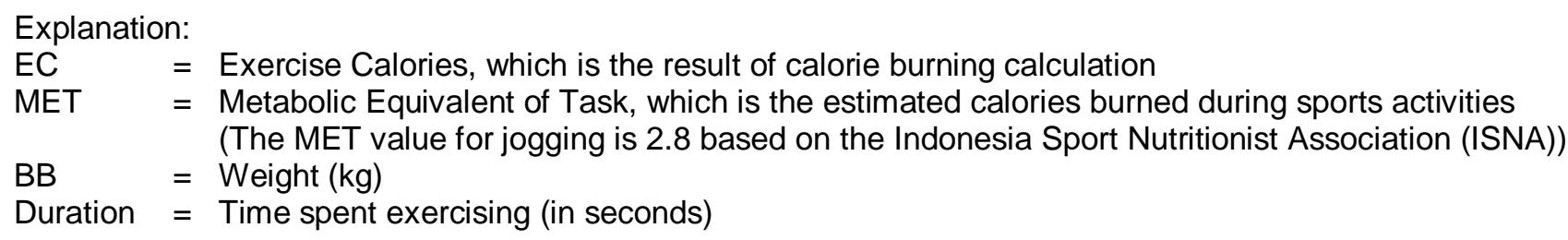

In previous research, for calories burned, calculated from the number of steps walking / running done every day. The steps are tracked using a mobile device accelerometer [9]. In addition, this calorie burning information will be calculated where the movements are detected by the accelerometer sensor during a particular exercise and are recorded along with the person's heart rate after each exercise [10]. Monitoring distance traveled by a person by walking and calories burned by walking, running or jogging. An algorithm is designed that links the movements of a person's arms with his feet when walking [11].

\subsection{Sensor Accelerometer and Magnitude Threshold}

An accelerometer sensor used to measure acceleration of an object. The working principle used is acceleration [12]. The operating threshold (acceleration and energy) is used for impact detection in the accelerometer smart sensor [13]. Current accelerometers are electromechanical devices that can measure static and linear / dynamic acceleration. The accelerometer sensor can be used to detect the tilt in the form of the angular values of the $\mathrm{X}, \mathrm{Y}$, and $\mathrm{Z}$ axes. The angular values are converted in the form of a waveform graph to easily determine the upper and lower threshold. From the three acceleration values, it is taken one of the axes then determined the threshold value for the upper and lower limits or can also be called the threshold above and threshold below. When conducting a trial run, the X-axis reads the data from the foot movements, if the upper and lower threshold values correspond to the specified threshold, then a foot step is detected. Then when walking, the resulting steps are multiplied by the average width of the foot when walking to calculate distance. The size of the footsteps is $78 \mathrm{~cm}$ on average or it is assumed to be a human step along the $0,78 \mathrm{~m}$. Then to calculate the number of calories burning, the number of steps, time taken, and initial body weight are needed. The coordinates of the accelerometer sensor can be seen in Figure 1 below.

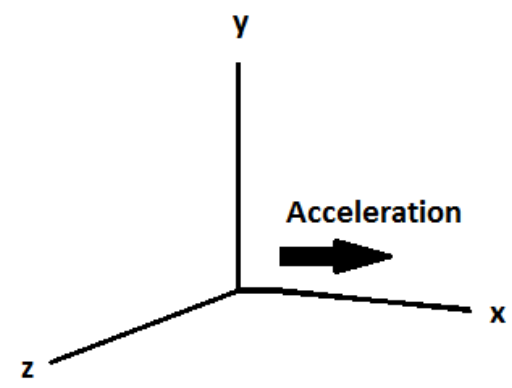

Figure 1. Accelerometer Axis

(C) 2020 The Authors. Published by Universitas Muhammadiyah Malang

This is an open access article under the CC BY SA license. (https://creativecommons.org/licenses/by-sa/4.0/) 
The accelerometer sensor is embedded in the smartphone to get more accurate fall detection results [14]. Triaxial accelerometer is used for smart belt systems, which can support the user's steps and flapping motion [15]. The smartphone's built-in accelerometer is also used to detect other user's physical movements such as jumping, spinning, etc [16]. The user's walking movements are detected through an android sensor, then analyzes the signal and calculates walking distance and calories burned [17]. In addition, a comprehensive fall detection system for elderly care is also integrated with the accelerometer sensor [18]. The process to detect a fall situation followed by sending notification to colleagues can be done in real-time manners while still maintain high accuracy for certain fall situations [19]. The use of theoretical models enables the optimization of high sensitivity accelerometer designs based on fiber Bragg grating (FBG) [20]. Through a combination of smart phones and sensors used, patients can provide feedback on their exercise program, while increasing medical monitoring [21].

On this system, it is given a threshold obtained from experiments and analyzes conducted previously that refer to the value of the accelerometer sensor on footsteps. After the threshold value is known, the threshold becomes a reference to know the foot step, if when the foot step counter is mounted to the user's foot and the accelerometer sensor value exceeds the threshold, the system will count as a foot step (value 1) and if the accelerometer sensor value is less than the threshold then the system will recognize that the user is not stepping (value 0 ).

\section{Research Method}

In this study, an application was developed an application using a smartphone as a data acquisition platform, because this device provides a user-friendly interface [22]. Smart phones with touch screens have become very popular and have changed people's behavior due to the many applications and features attached to them [23]. This application will count the number of footsteps taken as well as the number of burning calories produced during exercise, then monitored using the Android application. The presence of android smartphone technology that already supports the Accelerometer sensor which has accuracy in calculating footsteps on the android operating system [24]. The works way of this application is shown in Figure 2 below.

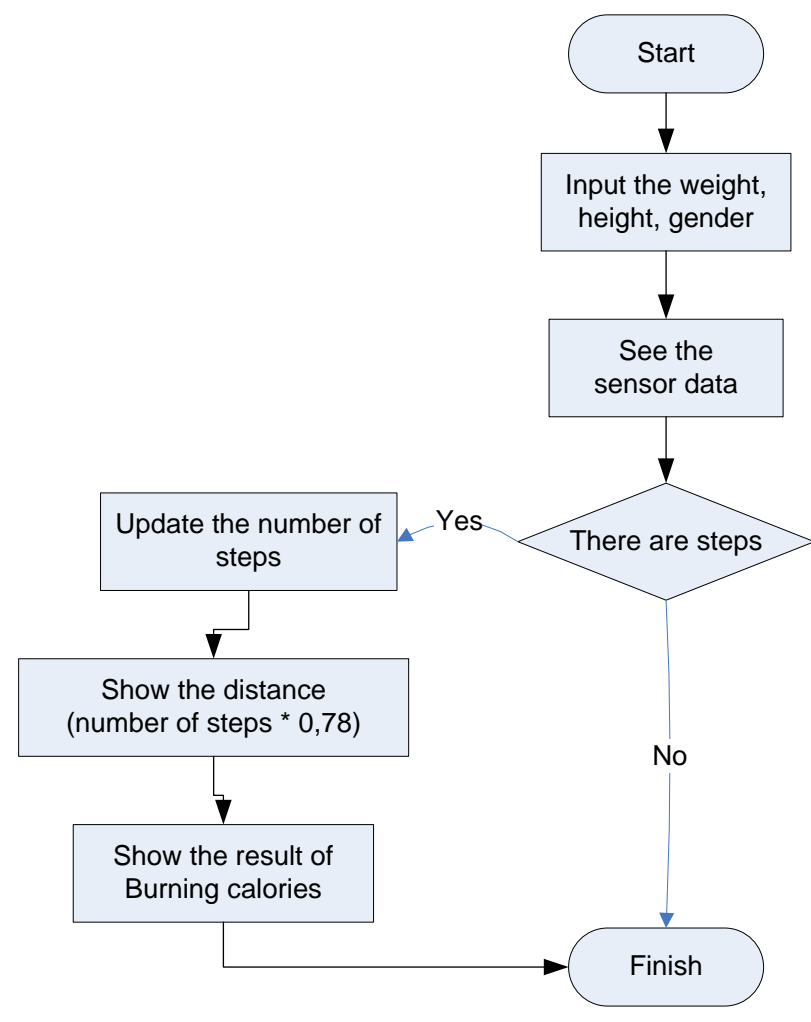

Figure 2. Flowchart Application

Figure 2 is the overall system that was developed in this study. At the beginning of this system, it was asked to input the of height, weight, and gender of the user. Then the athlete started jogging. During exercise, the accelerometer sensor worked to detect the number of footsteps. Next, the system displayed the total distance traveled based on these footsteps multiplied by 0,78 . And at the same time, the system $w$ also displayed the amount of burning calories produced during jogging.

Cite: Okmayura, F., Jefiza, A., \& Ramadhani, W. (2020). The calorie burning calculation system in jogging using a thresholding-based accelerometer sensor. Kinetik: Game Technology, Information System, Computer Network, Computing, Electronics, and Control, 5(2). 
Kinetik: Game Technology, Information System, Computer Network, Computing, Electronics, and Control

To know the results of calories burning, there were several steps that must be followed. First, determine the value of the magnitude. This value is used to determine the acceleration value in three axes, namely the $x, y$, and $z$ axes, each of which is symbolized in Ax, Ay, and Az.

\subsection{Determine the value of magnitude}

After the data is calculated based on the scale, the magnitude value of the xyz axis data on the accelerometer is calculated by using the following Equation 2 [25].

$$
A T t=\sqrt{a X^{2}+a Y^{2}+a Z^{2}}
$$

After the magnitude value was known, then the following curve can be seen in Figure 3.

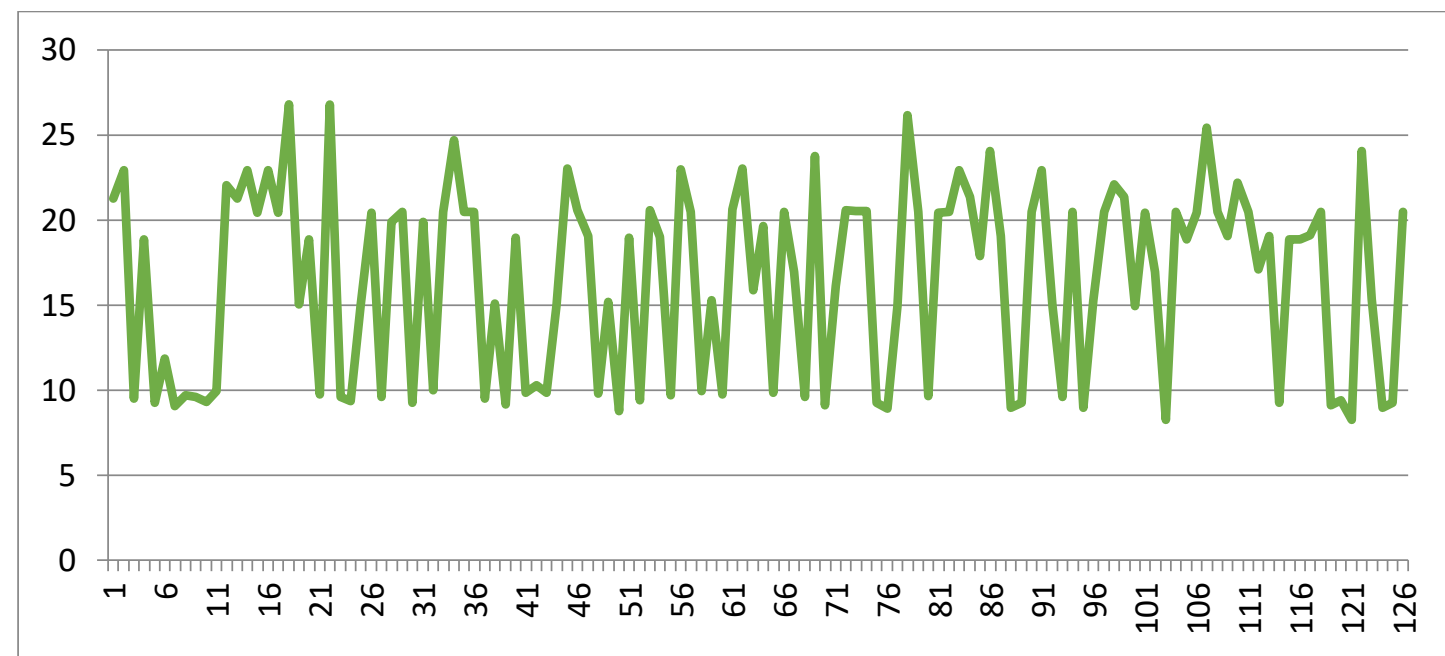

Figure 3. Data Sample Graph

The graph in Figure 3 above shows the value obtained in one jogging on the accelerometer sensor. The next step is to determine the threshold value.

\subsection{Determine the Threshold Value $(\Omega)$}

After the magnitude value was obtained, the next step was to look for the threshold value and it can be seen in Figure 4.

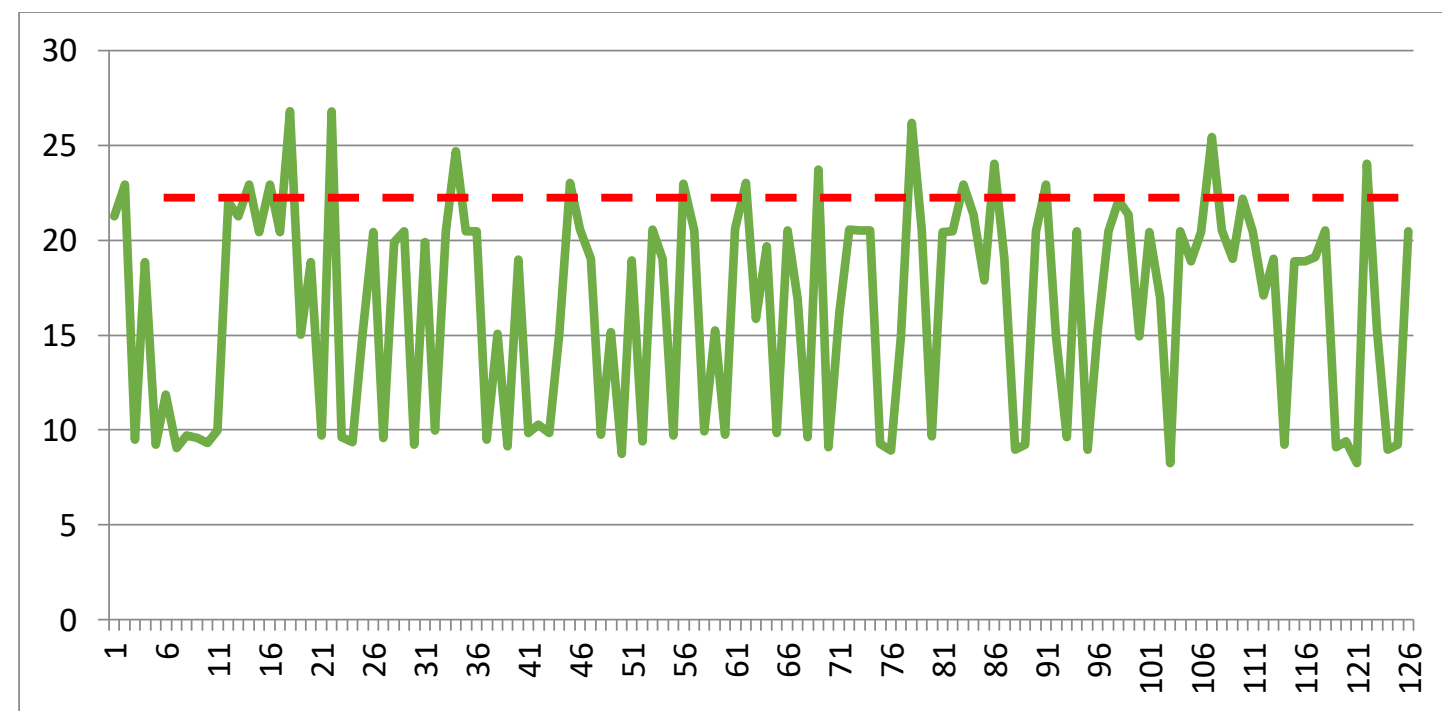

Figure 4. Graph when the Threshold Value was at $>20$ 
Threshold value was the threshold value used to determine steps. In this case the threshold value used was 20 . Determination of this threshold value is based on the average Att value obtained in the accelerometer sensor (based on Equation 2). If $\Omega>20$, then it was given a value of 1 , and if $\Omega<20$ then it was given a value of 0 . Furthermore, the threshold value of 1 was calculated as 1 step. Then the total steps were obtained by adding up all the threshold values of 1 . So that it was obtained 51 steps and the curve became in the form of zero (0) and one (1) logic pulse signals. So, the condition of the curve would be like the following Figure 5.

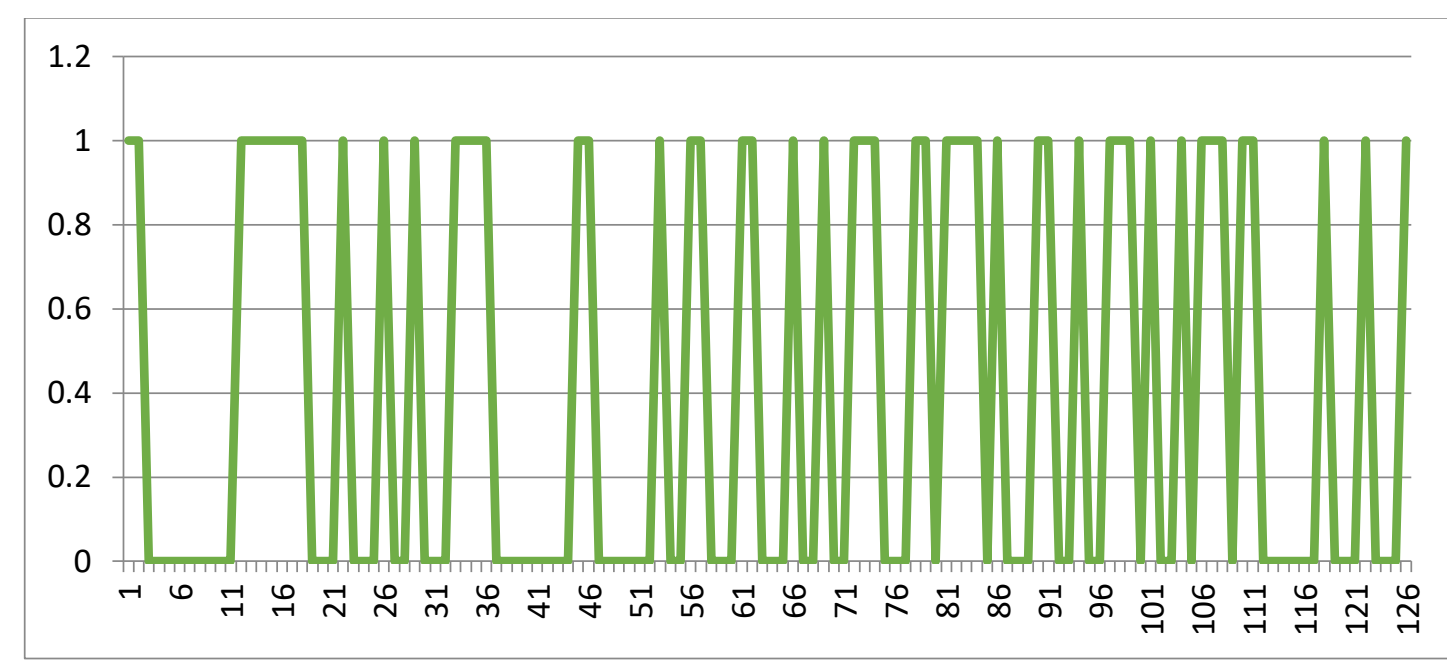

Figure 5. The Graph after the Threshold Value Changes to 0 and 1

\subsection{Determine the Total Jogging Distance}

After obtaining the number of footsteps, then the total distance traveled could be searched. Then when walking, the resulting steps were multiplied by the average width of the foot when walking to calculate distance. The United States customary units declare that the standardized unit of each human step is naturally calculated from the tip of the foot that is in front of the end of the previous leg. The size of the footsteps alone was on average $78 \mathrm{~cm}$ or it was assumed that a human step was $0,78 \mathrm{~m}$ long [7]. So, the formula for determining distance was as follows on Equation 3.

$$
\text { Distance }=\text { The Number of steps } x 0.78
$$

So, the distance traveled for jogging was $51 \times 0.78=39.78 \mathrm{~m}$

\subsection{Determining Calorie Burning Results}

Besides displaying distance, the application also displayed the results of calories burning. The following is a formula for calculating calorie burn symbolized by EC or Calorie Training obtained based on Equation 1.

$$
\begin{gathered}
E C=\left\{\text { METx } 7.7 \times \frac{(B B \times 2.2)}{200}\right\} \times \frac{\text { Duration }}{60} \\
E C=\left\{\begin{array}{c}
\left.2.8 \times 7.7 \times \frac{(65 \times 2.2)}{200}\right\} \times \frac{135}{60} \\
=21.56 \times 0.77 \times 2.25 \\
=37.3527 \mathrm{kcal}
\end{array}\right.
\end{gathered}
$$

\section{Results and Discussion}

The application of calorie burning calculation in jogging using a thresholding-based accelerometer sensor was called the Jogging Calories Burning Calculation (JCBC). The following was the display of the application when a new user first entered this JCBC application. It could be seen several menus in the application, namely jogging menu, health info and about us. Each menu has its own function. Before using this menu, the user must first fill in some data, namely name, age, gender, weight, and height. This data was useful to determine how the results of calories burning done by users during jogging by clicking on the start button first. After the start button is clicked, it is a sign that jogging has begun and footsteps start from here. How the application works can be seen in Figure 6 below.

Cite: Okmayura, F., Jefiza, A., \& Ramadhani, W. (2020). The calorie burning calculation system in jogging using a thresholding-based accelerometer sensor. Kinetik: Game Technology, Information System, Computer Network, Computing, Electronics, and Control, 5(2). doi:https://doi.org/10.22219/kinetik.v5i2.1005 
Based on Figure 6 above, after the user pressed the start button, the jogging application ran, then on the smartphone screen, it could be seen the jogging sport time and the number of steps during exercise. When the user finished doing jogging, the information and the page of the calorie burning results were appeared. Not only information on burning calories during jogging, the application also provided the information of the time, the total steps and the total distance taken during jogging.
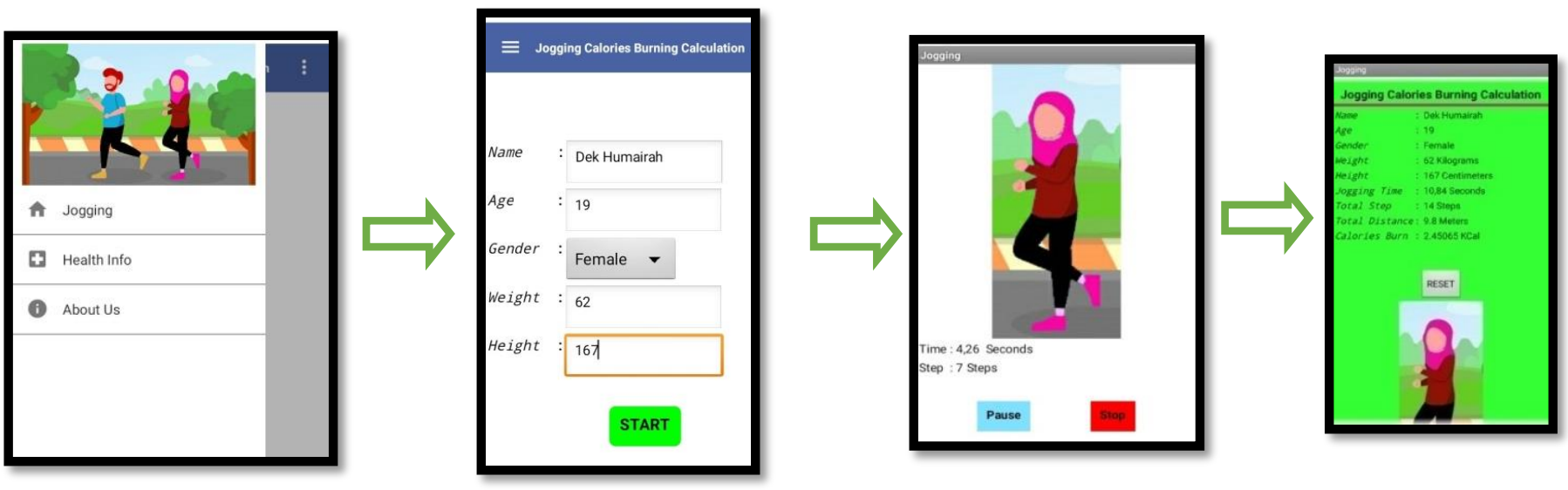

Figure 6. Application of JCBC

To strengthen the accuracy of the results of calorie burning applications in jogging using this threshold-based accelerometer sensor, the researchers tested it with several participants. This test compares the amount of calorie burning in the JCBC application with a manual calculation based on Equation 1. This test can be seen in the following Table 1.

Table 1. Testing Applications for Manual Calculations

\begin{tabular}{cccccccc}
\hline No. & Nama & Gender & $\begin{array}{c}\text { Weight } \\
(\mathrm{kg})\end{array}$ & $\begin{array}{c}\text { Duration } \\
\text { (second) }\end{array}$ & $\begin{array}{c}\text { The Number } \\
\text { Calorie } \\
\text { Burning in } \\
\text { Application }\end{array}$ & $\begin{array}{c}\text { The } \\
\text { Number } \\
\text { Calorie } \\
\text { Burning in } \\
\text { manual }\end{array}$ & $\begin{array}{c}\text { Error } \\
\text { Percentage }\end{array}$ \\
\hline 1 & Participant 1 & P & 55 & 219 & 47,60987 & 47,60 & $0,98 \%$ \\
2 & Participant 2 & L & 65 & 478 & 122,80935 & 122,80 & $0,93 \%$ \\
3 & Participant 3 & L & 70 & 131 & 36,24595 & 36,24 & $0,59 \%$ \\
4 & Participant 4 & L & 66 & 90 & 23,47884 & 23,47 & $0,88 \%$ \\
5 & Participant 5 & P & 62 & 113 & 27,69238 & 27,69 & $0,23 \%$ \\
6 & Participant 6 & L & 60 & 122 & 28,93352 & 28,93 & $0,35 \%$ \\
7 & Participant 7 & P & 58 & 143 & 32,78342 & 32,78 & $0,34 \%$ \\
8 & Participant 8 & L & 49 & 412 & 79,79643 & 79,79 & $0,64 \%$ \\
9 & Participant 9 & L & 56 & 141 & 31,21026 & 31,21 & $0,02 \%$ \\
10 & Participant 10 & P & 58 & 323 & 74,04926 & 74,04 & $0,92 \%$ \\
11 & Participant 11 & P & 63 & 267 & 66,48781 & 66,48 & $0,78 \%$ \\
12 & Participant 12 & P & 65 & 158 & 40,59389 & 40,59 & $0,38 \%$ \\
13 & Participant 13 & L & 71 & 214 & 60,05682 & 60,05 & $0,68 \%$ \\
14 & Participant 14 & P & 62 & 542 & 132,82541 & 132,82 & $0,54 \%$ \\
15 & Participant 15 & P & 60 & 388 & 92,01808 & 92,01 & $0,80 \%$ \\
\hline
\end{tabular}

Based on testing that has been done 15 times according to Table 1, it can calculate the error value or the difference in the value of the entire calculation in this system with the Equation 4 as follows.

$$
\begin{gathered}
\text { Percentage of overall error }=\frac{\sum \text { error value }}{\sum \text { testing }} \\
\text { Percentage of overall error }= \\
\begin{array}{c}
0,98+0,93+0,59+0,88+0,23+0,35+0,34+0,64+0,02+0,92+0,78+0,38+0,68+0,54+0,80 \\
=0,60 \%
\end{array}
\end{gathered}
$$

(c) 2020 The Authors. Published by Universitas Muhammadiyah Malang

This is an open access article under the CC BY SA license. (https://creativecommons.org/licenses/by-sa/4.0/) 
Based on calculations in Equation 4 above, the overall error value in testing this system is $0.60 \%$, so it can be concluded that this system $99.40 \%$ of applications can be used and is worthy of being used as a tool for athletes when jogging to find out the calorie burning results during exercise.

\section{Conclusion}

By using this Jogging Calories Burning Calculation (JCBC) application, researchers hoped that this application can make it easier for athletes to get their calorie burning information while jogging. From the results of tests that have been carried out, it was found that the calorie burning results in the application were in accordance with manual calculations based on body weight and there was no differences, so it could be concluded that this application was suitable and fit for athletes when jogging to find out the results of burning calories during exercise.

\section{Acknowledgement}

The researchers thanked to the Directorate of Research and Community Service, the Directorate General of Research and Development of the Ministry of Research, Technology and Higher Education, for funding this research in 2019 entitled the calorie burning calculation system in jogging using a thresholding-based accelerometer sensor.

\section{References}

[1] A. P. Fakhrun Nisa'ul Azizah, Tubagus Mohammad Akhriza, "Aplikasi Android Untuk Membantu Program Diet Berbasis Aktifitas," No. September, Pp. 587-597, 2017.

[2] F. A. Zakaria, Shahreen Kasim, "Daily Calorie Manager for basic daily use," Third Int. Conf. Innov. Comput. Technol. (INTECH 2013). IEEE, No. Augustus, Pp. 437-442, 2013. https://doi.org/10.1109/INTECH.2013.6653675

[3] M. Chattopadhyay, Yash Jain, Debjyoti Chowdhury, "Machine Learning Based Fitness Tracker Platform Using MEMS Accelerometer," 2017 Int. Conf. Comput. Electr. Commun. Eng. (ICCECE). IEEE, Pp. 1-5, 2017. https://doi.org/10.1109/INTECH.2013.6653675

[4] K. L. Achari, G.Karthik Reddy, "A non invasive method for calculating calories burned during exercise using heartbeat," 2015 IEEE 9th Int. Conf. Intell. Syst. Control (ISCO). IEEE, 2015. https://doi.org/10.1109/ISCO.2015.7282249

[5] W. A. Kusuma and S. N. Ubay, "Monitoring Langkah Kaki Dengan Sensor Mpu6050 Untuk Menghitung Jumlah Kalori," Pp. 50-55, 2018. https://doi.org/10.22219/sentra.v0i4.2285

[6] R. Setola, Francesca De Cillis, Francesca De Simio, Floriana Guido, Raffaele Antonelli Incalzi, "Fall-detection solution for mobile platforms using accelerometer and gyroscope data," 2015 37th Annu. Int. Conf. IEEE Eng. Med. Biol. Soc. (EMBC). IEEE, Pp. 3727-3730, 2015. https://doi.org/10.1109/EMBC.2015.7319203

[7] W. A. Kusuma and Z. Sari, "Monitoring Walking Devices For Calorie Balance In Patients With Medical Rehabilitation Needs," Pp. 460-463, 2018. https://doi.org/10.1109/EECSI.2018.8752761

[8] T. Rahman and D. Kurniawan, "Perancangan Pedometer Berbasis Sensor Accelorometer Android," Vol. 2, No. 2, Pp. 122-130, 2017. http://ejournal.nusamandiri.ac.id/index.php/jitk/article/view/392

[9] W. Kusakunniran, Benjarat Tirasirichai , Peeraya Thanomboon, Pimpaknat Soontorntham, "Bloom Balance: Calorie Balancing Applic ation With Scientific Validation," 2018 15th Int. Jt. Conf. Comput. Sci. Softw. Eng. (JCSSE).IEEE, Pp. 1-6. . https://doi.org/10.1109/JCSSE.2018.8457177

[10] R. Udasi, Saarah Reiaz, Ilef Mcharek, Ruqaiya Shabbir, Hock Chuan Lim, Debobroto Talukder, "CalorieKiller: Burning Calories using Mobile Exergame with Wearables," 2019 IEEE 7th Int. Conf. Serious Games Appl. Heal. (SeGAH). IEEE, Pp. 1-5, 2019. https://doi.org/10.1109/SeGAH.2019.8882453

[11] K. P. R Pawan Sai, Suma Bapanapalle, "Pedometer and calorie calculator for fitness tracking using MEMS digital accelerometer," 2016 Int. Conf. Inven. Comput. Technol. (ICICT). IEEE, Vol. 1, Pp. 1-6, 2016. https://doi.org/10.1109/INVENTIVE.2016.7823237

[12] M. I. Khalif, D. Syauqy, and R. Maulana, "Pengembangan Sistem Penghitung Langkah Kaki Hemat Daya Berbasis Wemos D1 Mini," Vol. 2, No. 6, Pp. 2211-2220, 2018

[13] M. A. Estudillo, D. Naranjo, L. M. Roa, L. J. Reina-Tosina, "Optimization procedure for the impact detection thresholds in an Accelerometer Smart Sensor," 2009 9th Int. Conf. Inf. Technol. Appl. Biomed. IEEE, Pp. 1-4, 2009. https://doi.org/10.1109/ITAB.2009.5394354

[14] W. Kurnianingsih, Arkham Zahri Rakhman, Lukito Edi Nugroho, "Fall detection system using accelerometer and gyroscope based on smartphone," 2014 1st Int. Conf. Inf. Technol. Comput. Electr. Eng. IEEE, Pp. 99-104, 2014. https://doi.org/10.1109/ICITACEE.2014.7065722

[15] A. Huang, Botong Liu, Duo Wang, Sha Li, Xuhui Nie, Shan Xu, Bingli Jiao, Xiaohui Duan, "Design and implementation of an intelligent belt system using accelerometer," 2015 37th Annu. Int. Conf. IEEE Eng. Med. Biol. Soc. (EMBC). IEEE, Pp. $2043-2046,2015$. https://doi.org/10.1109/EMBC.2015.7318788

[16] N. S. C. P. Pamidi, Pradeep Buddharaju, "Mobile Exergames - Burn Calories While Playing Games on a Smartphone," 2013 IEEE Conf. Comput. Vis. Pattern Recognit. Work. IEEE, Pp. 50-51, 2013. https://doi.org/10.1109/CVPRW.2013.13

[17] H.-Y. Wu, Shyi-Shiou Wu, "The Design of an Intelligent Pedometer Using Android," 2011 Second Int. Conf. Innov. Bio-inspired Comput. Appl. IEEE, Pp. 313-315, 2011. https://doi.org/10.1109/IBICA.2011.83

[18] R. Pan, Thinh M. Le, "Accelerometer-based sensor network for fall detection," 2009 IEEE Biomed. Circuits Syst. Conf. IEEE, Pp. 265-268, 2009. https://doi.org/10.1109/BIOCAS.2009.5372032

[19] R. M. Ijtihadie, Waskitho Wibisono, Dedy Nur Arifin, Baskoro Adi Pratomo, Tohari Ahmad, "Falls Detection and Notification System Using Triaxial Accelerometer and Gyroscope Sensors of a Smartphone," 2013 Conf. Technol. Appl. Artif. Intell. IEEE, Pp. 382-385, 2013. https://doi.org/10.1109/TAAI.2013.82

[20] K. T. V. Grattan, Qinpeng Liu, Xue He, Xueguang Qiao, Tong Sun, "Design and Modeling of a High Sensitivity Fiber Bragg Grating-Based Accelerometer. IEEE," IEEE Sens. J., Vol. 19, No. 14, Pp. 5439-5445. https://doi.org/10.1109/JSEN.2019.2904218

[21] M. Song, Sheng Zhong, Li Wang, Ana M. Bernardos, "An accurate and adaptive pedometer integrated in mobile health application. IEEE," IET Int. Conf. Wirel. Sens. Netw. 2010 (IET-WSN 2010). IEEE. https://doi.org/10.1049/cp.2010.1032

[22] R. E. Hillman, Daryush D. Mehta, Matías Zañartu, Shengran W. Feng, Harold A. Cheyne II, "Mobile Voice Health Monitoring Using a Wearable Accelerometer Sensor and a Smartphone Platform," IEEE Trans. Biomed. Eng. IEEE, Vol. 59, No. 11, Pp. $3090-3096$. https://doi.org/10.1109/TBME.2012.2207896

[23] R. Jasutkar, Monali P. Admane, "Speech to text and accelerometer based smart phone interaction system," Int. Conf. Inf. Commun. Embed. Syst. (ICICES2014). IEEE, Pp. 1--4. https://doi.org/10.1109/ICICES.2014.7033916

Cite: Okmayura, F., Jefiza, A., \& Ramadhani, W. (2020). The calorie burning calculation system in jogging using a thresholding-based accelerometer sensor. Kinetik: Game Technology, Information System, Computer Network, Computing, Electronics, and Control, 5(2). doi:https://doi.org/10.22219/kinetik.v5i2.1005 
110 Kinetik: Game Technology, Information System, Computer Network, Computing, Electronics, and Control

[24] M. Dwiki, S. Olajuwon, A. R. Atmadja, A. Wahana, and J. A. H. N. Bandung, "Aplikasi Pendeteksi Kalori Terbakar dengan Smartphone Menggunakan Sensor Accelerometer dan Pedometer," Vol. 1, No. 1, Pp. 148-154, 2018. . https://doi.org/10.15575/insight.v1i1.62

[25] M. H. Purnomo, Adlian Jefiza, Eko Pramunanto, Hanny Boedinoegroho, "Fall detection based on accelerometer and gyroscope using back propagation," 2017 4th Int. Conf. Electr. Eng. Comput. Sci. Informatics (EECSI). IEEE, Pp. 1-6, 2017. https://doi.org/10.1109/EECSI.2017.8239149 